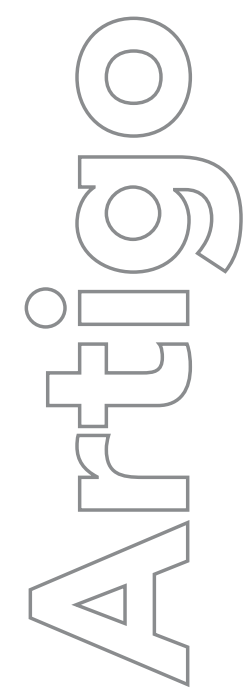

revista

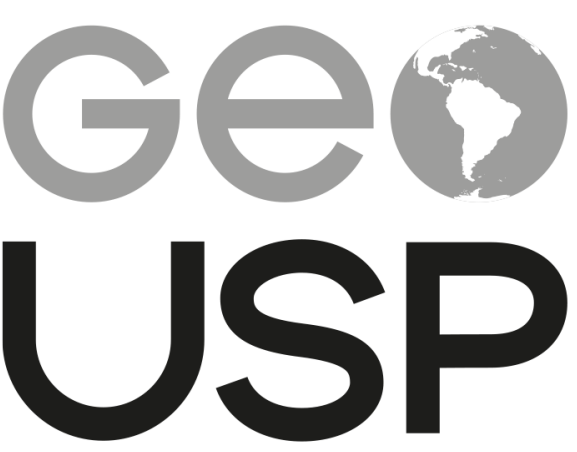

espaço e tempo

Volume $25 \cdot n^{\circ} 3(2021)$

ISSN 2179-0892

\section{A oferta de Airbnb como expressão da gentrificação e da turistificação em Paris}

\section{Eugênia Dória Viana Cerqueira \\ Instituto de Geociências \\ Universidade Federal de Minas Gerais Belo Horizonte. Minas Gerais. Brasil \\ eugeniadoria@gmail.com \\ (1) 0000-0003-0306-4766}

\section{e-186396}

Como citar este artigo:

CERQUEIRA, E. D. V. A oferta de Airbnb como expressão da gentrificação e da turistificação em Paris. Geousp, v. 25, n. 3, e-186396, dez. 2021. ISSN 2179-0892. Disponível em: https://www.revistas.usp.br/geousp/ article/view/186396. doi:https://doi.org/10.11606/issn. 2179-0892.geousp.2021.186396.

\section{(c) (1)}

Este artigo está licenciado sob a Creative Commons Attribution 4.0 License. 


\title{
A oferta de Airbnb como expressão da gentrificação e da turistificação em Paris
}

\section{Resumo}

Nos últimos anos, a disseminação de Airbnb em diversas cidades do mundo suscitou uma série de questionamentos acerca da relação entre o crescimento acelerado da oferta de unidades de aluguel de curto prazo e o processo de gentrificação. Este trabalho objetiva investigar a articulação entre a valorização urbana pelo turismo em Paris traçando um paralelo entre a evolução geográfica da oferta de unidades de locação de curto prazo e os processos socioespaciais ligados à gentrificação. Pela análise quantitativa multivariada, demonstra-se que a expansão centrífuga da oferta de Airbnb em direção às periferias parisienses coincide com evoluções socioeconômicas intrínsecas ao processo de gentrificação, como o aumento do valor médio dos imóveis e da renda média dos habitantes e a expulsão da população imigrante.

Palavras-chave: Gentrificação. Turistificação. Airbnb. Neoliberalismo. Paris.

\section{The Airbnb offer as an expression of gentrification and turistification in Paris}

\begin{abstract}
In recent years, the spread of Airbnb in several cities around the world has raised a number of questions about the relationship between the accelerated growth in the supply of short-term rental units and the gentrification process. This study aims at investigating the relationship between the urban valorization by tourism in Paris, drawing a parallel between the geographic evolution of the offer of short-term rental units and the socio-spatial processes linked to gentrification. A multivariate quantitative analysis is developed to demonstrate that the centrifugal expansion of the Airbnb offer towards the Parisian peripheries coincides with socioeconomic indicators of the gentrification process, such as the increase in average land values, the average income of the inhabitants and the expulsion of immigrant population.
\end{abstract}

Keywords: Gentrification. Touristification. Airbnb. Neoliberalism. Paris. 


\section{L'offre d'Airbnb comme l'expression de la gentrification et la touristification à Paris}

\section{Résumé}

Ces dernières années, la diffusion de l'Airbnb dans plusieurs villes du monde a soulevé un certain nombre de questions sur la relation entre la croissance accélérée de l'offre de locations de courte durée et le processus de gentrification. Cet article vise à analyser l'articulation entre la valorisation urbaine par le tourisme à Paris, en établissant un parallèle entre l'évolution géographique de l'offre de logements locatifs de courte durée et les évolutions socio-spatiales liées à la gentrification. À partir d'une analyse quantitative multivariée, on démontre que l'expansion centrifuge de l'offre d'Airbnb vers les périphéries parisiennes coïncide avec les évolutions socioéconomiques intrinsèques au processus de gentrification, telles que l' augmentation de la valeur moyenne des biens, des revenus médians des habitants et l'expulsion de la population immigrée.

Mots-clés: Gentrification. Touristification. Airbnb. Néolibéralisme. Paris.

\section{Introdução}

Nas últimas décadas, a literatura acadêmica tem evidenciado o processo de gentrificação turística (Gotham, 2005), caracterizado pela transformação de bairros populares, centrais e históricos em locais de consumo, lazer e turismo. $\bigcirc$ turismo é utilizado como um mecanismo catalisador das dinâmicas de renovação urbana, engendrando um aumento exponencial das rendas e multiplicando expulsões de moradores vulneráveis e fechamentos de locais comerciais tradicionais. Nesse cenário, a recente disseminação de plataformas de aluguel de acomodações a curto prazo, como o Airbnb, tem um papel capital na reprodução da dinâmica em tela. Uma série de investigações aponta os principais impactos da difusão do Airbnb no mercado imobiliário e no preço dos aluguéis (Delgado-Medrano; Lyon, 2016; Wachsmuth; Weisler, 2018), destacando que a difusão de unidades aluguel a curto prazo tem contribuído com a expulsão dos residentes de regiões turísticas em diversas cidades do mundo.

O objetivo deste artigo é elucidar a relação entre a disseminação recente de unidades Airbnb e o processo de gentrificação na cidade de Paris. A capital francesa, visitada por mais de 100.000 pessoas por dia, figura como a segunda cidade no mundo com o maior número de listagens Airbnb, atrás apenas de Londres. Sob essa ótica, questiona-se se a dinâmica de expansão exponencial das unidades de locação de curto prazo observada nos últimos anos incide na dinâmica global de gentrificação, já bem documentada na cidade-luz (Clerval, 2013). Para validar essas premissas, emprega-se uma análise multivariada que conjuga dados sociodemográficos e 
imobiliários à expansão da oferta de unidades Airbnb na capital de 2015 a 2019. ${ }^{1}$ À metodologia quantitativa, conjuga-se uma análise qualitativa que ilustra, com os bairros Marais e Belleville, a articulação entre o fenômeno de gentrificação e a turistificação na capital francesa. A reflexão é calcada num breve levantamento de matérias em veículos de comunicação parisienses e numa série de entrevistas semiestruturadas tomadas em campo.

Num primeiro momento, discute-se a recente difusão de unidades de locação de curto prazo em várias cidades do mundo e seu impacto nos processos de gentrificação e turistificação. Depois, contextualiza-se o tema em Paris, que assiste a um processo de expansão geográfica da oferta de unidades Airbnb nos últimos cinco anos. Por fim, se faz uma análise multivariada visando articular a disseminação de unidades de aluguel de curto prazo com processos socioespaciais indicadores da gentrificação.

\section{Aumento exponencial das habitações de aluguel de curto prazo e seu impacto no processo de gentrificação}

\section{Processo de turistificação e dinâmicas de gentrificação}

Nas últimas duas décadas, disseminaram-se as investigações acerca da gentrificação, conceito introduzido em 1964 por Ruth Glass (1964) para designar a alteração na composição socioeconômica e urbana de bairros e distritos pelo afluxo de residentes e atividades de alta renda e da consequente dificuldade de manutenção de moradores de baixa renda. A gentrificação emerge como fruto de diversos processos recentes como a globalização, adquirindo um papel ímpar na produção de mais-valia do mercado imobiliário e na estruturação econômica das grandes aglomerações. De acordo com Smith (1987), o processo baseia-se no chamado rent gap, ou a disparidade entre a renda da terra potencial e a renda da terra capitalizada no presente uso.

Sob essa ótica, o processo de gentrificação assume diferentes contornos em três grandes etapas sucessivas (Smith, 1996). A primeira fase, identificada no início dos anos 1960, abarca um processo espontâneo, não planificado, de gentrificação. A segunda fase, iniciada na década de 1980, é denominada fase de ancoragem, ganhando uma maior sistematização. Já no final dos anos 1990, a gentrificação passa de um processo casual e local para uma estratégia urbana global, diretamente articulada aos circuitos do capital global e da circulação cultural. Pautada pela dialética entre as dinâmicas do capital financeiro na escala global e a produção do espaço urbano na escala local, no contexto contemporâneo, a gentrificação não se reduz às dinâmicas residenciais, abrangendo outros elementos da geografia funcional da cidade como o comércio, o turismo e a governança (Mendes, 2017).

Nos anos 2000, Gotham (2005) formulou o conceito de gentrificação turística a fim de destacar o papel da política estatal no incentivo ao desenvolvimento do turismo e, consequentemente, à gentrificação. Sob essa ótica, o turismo seria uma estratégia de renovação urbana, engendrando

1 Os dados utilizados são do ano de 2019, pois o contexto da pandemia do coronavírus, que se agravou no início de 2020, interferiu fortemente na dinâmica de locação em curto prazo nas grandes metrópoles de todo o mundo. 
um aumento exponencial da renda, a multiplicação da expulsão de moradores vulneráveis e o fechamento de locais comerciais tradicionais. $\bigcirc$ referido processo caracteriza-se pela transformação de bairros populares, centrais e históricos em locais de consumo, lazer e turismo, sob a égide de dinâmicas simultâneas de globalização e valorização local. Por um lado, o turismo inscreve-se em uma indústria global, dominada por grandes cadeias hoteleiras internacionais, operadoras de turismo, empresas de serviços financeiros, locadoras de veículos etc. Por outro lado, trata-se de uma indústria calcada na escala local, caracterizada pela produção cultural de base e pela fixidez espacial da mercadoria turística e consumo localizado do lugar. Desse modo, os processos de gentrificação urbana e exploração turística passaram a atuar conjuntamente no espaço urbano, superando gradualmente locais tradicionalmente turísticos. Segundo Martins (2019), nas últimas décadas constata-se a inscrição de novos locais em uma rota turística global turística, diretamente articulada aos processos de gentrificação.

Na última década, uma série de autores assinala a articulação entre dinâmicas de turismo e gentrificação em várias cidades do mundo, principalmente em áreas com alto valor patrimonial. Mendes (2017) defende que na cidade de Lisboa os fluxos de capital no mercado imobiliário, articulados às transformações econômicas e às políticas de incentivo ao turismo explicam de maneira mais sólida as dinâmicas atuais de gentrificação na cidade do que as hipóteses tradicionais que associam o fenômeno à demanda gerada pelos chamados gentrifiers. Assim, a discussão acerca do turismo opõe grupos que lucram o fluxo de visitantes e com as operações de renovação urbana a grupos que denunciam os efeitos negativos da atividade turística (Mendes, 2017). A resistência social a esse fenômeno pode estar ligada ao impacto sociourbano da especulação turística: financeiro (especulação imobiliária e aumento do preço das propriedades), social (despejos, saturação do sistema de transporte público) e funcional (transformação simbólica e comercial).

A literatura acadêmica vem elucidando o papel do aumento substancial de alojamentos turísticos na dinâmica de gentrificação, particularmente aluguéis de curta duração, que substituem gradualmente as funções tradicionais da habitação para uso permanente (Yrigoy, 2016). A disseminação de plataformas de aluguel de curto prazo, como o Airbnb, impulsiona um novo tipo de capitalização de locações para turistas, agravando tendências de segregação residencial e de desalojamento de grupos de baixa renda.

\section{Ascensão da economia compartilhada e gentrificação}

A possibilidade de compartilhar bens, serviços e ativos de propriedade privada entre indivíduos remonta a antigas formas de comércio como locadoras de automóveis, locais de hospedagem, lavanderias. Na última década, a articulação entre uma pluralidade de fatores, como a proliferação da internet e de tecnologias móveis, o avanço do processo de globalização, a crise econômica global e mudanças generalizadas nos comportamentos de consumo ensejaram a ascensão e consolidação da chamada economia de compartilhamento (Ranjbari; MoralesAlonso; Carrasco-Gallego, 2018). A crescente noção de economia do compartilhamento é pautada no conceito de consumo colaborativo, que pode ser definido como o acesso temporário a bens e serviços para uso dos consumidores ordenado por plataformas on-line (Hamari; Sjöklint; Ukkonen, 2015). A principal inovação da economia do compartilhamento consiste na inserção 
de plataformas digitais, que fornecem aos consumidores a possibilidade de compartilhar uma imensa variedade de produtos e serviços, permitindo uma articulação mais eficiente entre oferta e demanda (Folgueira; Silva; Carvalho, 2019).

Com efeito, plataformas como o Airbnb despontaram nos últimos anos como umas das principais companhias de economia compartilhada, propiciando a partilha temporária de acomodações, que podem consistir em imóveis inteiros, quartos privados, quartos compartilhados e mesmo acomodações exóticas como barcos, casas em árvores etc. Nos últimos cinco anos, a plataforma apresentou um crescimento exponencial de usuários, atingindo o marco de 500 milhões de hóspedes em 2019 (Airbnb comemora..., 2019). O fenômeno do Airbnb deve ser entendido não só como parte da economia colaborativa, mas como uma tradução da aspiração dos turistas a desfrutar de acomodações de caráter menos comercial que as tradicionais do setor hoteleiro (Hamari; Sjöklint; Ukkonen, 2015).

Devido ao aumento exponencial de unidades Airbnb em escala planetária, o potencial disruptivo dessa oferta recebeu considerável atenção na literatura acadêmica nos últimos anos, principalmente no que diz respeito aos desafios e possíveis impactos do crescimento acelerado da plataforma (Guttentag, 2013; Meleo; Romolini; De Marco, 2016). Recentemente, diversos estudos apontaram os principais impactos da difusão do Airbnb no mercado imobiliário e no preço dos aluguéis (Delgado-Medrano; Lyon, 2016; Wachsmuth; Weisler, 2018), destacando que a difusão de unidades Airbnb tem contribuído com a expulsão dos residentes de regiões turísticas em diversas cidades do mundo (Delgado-Medrano; Lyon, 2016; Oskam; Boswijk, 2016; Wachsmuth; Weisler, 2018). Apontam-se as tensões decorrentes da expansão do Airbnb em cidades como São Francisco e Nova York, onde coexistem altas demandas de hospedagem para turistas e para habitação regular.

Alicerçada na produção de novos fluxos de renda por meio da propriedade privada, a lógica do Airbnb, articula-se diretamente com a já citada teoria do rent gap. $\bigcirc$ debate fornece evidências circunstanciais de que o aluguel de curto prazo vincula-se ao processo de gentrificação em diversas cidades do mundo, principalmente aquelas que se inserem em circuitos turísticos locais e globais. Wachsmuth e Weisler (2018) enfatizam que, nos últimos anos, o Airbnb forneceu um meio de preencher novas lacunas de aluguel, aumentando a renda potencial dos locadores sem a necessidade de renovar os bens em questão e de forma geograficamente desigual, concentrando-se em bairros com apelo turístico extralocal, que não necessariamente se sobrepõem a áreas que se beneficiam.

O fato de o aluguel de curto prazo ter produzido um novo fluxo potencial de receita no mercado imobiliário sugere que serviços como o Airbnb poderiam engendrar disparidades de aluguel nas cidades do mundo todo. Sob essa ótica, em áreas em processo de gentrificação, a nova oferta de bens de aluguel de curto prazo eleva sistematicamente os aluguéis em potencial, mesmo em áreas nas quais se observa pouca valorização da habitação existente. A renda mensal de propriedades de aluguel de curto prazo pode exceder substancialmente o que poderia ser obtido por arrendamento residencial convencional de longo e médio prazo, particularmente em cidades com forte regime de controle de aluguéis. 
Nesse sentido, a atuação do Airbnb como fator catalisador da gentrificação que acarreta a substituição de residentes por turistas tem sido amplamente discutida na literatura acadêmica nos últimos anos. Wachsmuth e Weisler (2018) mostram que, em Nova York, o Airbnb tem captado uma porcentagem significativa das unidades de habitação disponíveis para aluguel. Além disso, verifica-se uma redistribuição espacial dos aluguéis de curto prazo em áreas historicamente pouco turísticas. Em Barcelona, o governo municipal introduziu uma série de medidas regulamentares para mitigar os efeitos da gentrificação turística na cidade. Em 2018, o Ministério da Finança instituiu a obrigação de declarar o uso turístico de imóveis residenciais (Blanco-Romero; Blázquez-Salom; Cànoves, 2018). Em 2017, aprovou-se o Plano Especial para Acomodações Turísticas (Peuat) no intuito de compatibilizar a difusão crescente de acomodações turísticas com o desenvolvimento urbano sustentável. Configurado como um instrumento de planejamento urbano, o Peaut distingue zonas na cidade segundo a ocupação socioespacial, determinando, assim, o número de imóveis destinados ao turismo que podem ser implementados em cada área.

Ademais, com o estudo de caso de Lisboa, Cocola-Gant e Gago (2019) mostram que o Airbnb têm se tornado um instrumento que contribui para a financiarização de moradias e que os fornecedores de aluguel de curto prazo tratam-se principalmente investidores que utilizam a habitação como um ativo para o armazenamento de capital. Assim, a plataforma reforça o paradigma neoliberal aumentando a eficiência do mercado para os proprietários de capital imobiliário e moldando um mercado de aluguel cada vez mais flexível que, para os inquilinos, implica menos estabilidade. Verifica-se que proprietários que vendem seus bens imobiliários para investidores atuam como catalisadores da emigração de residentes, uma vez que se rarefaz o mercado tradicional de aluguel privado de habitações. Esse processo leva a uma mudança no uso da terra, de residencial para turístico, com impacto direto nas dinâmicas socioespaciais locais.

\section{Resultados}

\section{Cartografia das unidades Airbnb em Paris}

Paris se insere no contexto das diversas metrópoles que, nas últimas décadas, viram a difusão gradual do fenômeno de gentrificação em suas áreas centrais, constituindo um objeto de análise recorrente. Identifica-se claramente um movimento centrífugo que caracteriza a permutação das classes populares, que ultrapassam as fronteiras administrativas dos 20 arrondissements do núcleo da metrópole (Clerval, 2013). Verificou-se, assim, uma extensão espacial das tendências de gentrificação, que englobaram bairros tradicionalmente populares e caracterizados pela presença de população imigrante, como Belleville e La Goutte d' Or. ${ }^{2}$ Assim, o processo supracitado embasa-se em temporalidades distintas, uma vez que coexistem espaços de gentrificação consumada e gentrificação em processo de emergência.

2 Ressalte-se que, no contexto parisiense, os bairros populares são caracterizados por um contingente de imigrantes superior à média da cidade. 
Em paralelo, constata-se um aumento expressivo do número de unidades para locação de curto prazo na cidade nos últimos anos. Paris tem mais de 100.000 visitantes por dia, fator que incide diretamente nas dinâmicas econômicas da cidade, mas também na configuração do espaço urbano. De acordo com dados da plataforma Inside Airbnb ([s.d.]), é a segunda cidade no mundo com o maior numero de listagens Airbnb (59.881 listagens), sendo ultrapassada apenas por Londres, com 87.235 unidades listadas. A grande maioria das unidades Airbnb parisienses são apartamentos inteiros (86,8\%), com uma taxa de ocupação de aproximadamente 25\%. Além disso, 20\% dos anfitriões Airbnb em Paris têm diversas unidades anunciadas na plataforma, tendo o mais popular 173 listagens simultâneas.

A metodologia desenvolvida nesta investigação usa a plataforma Inside Airbnb, que fornece dados geolocalizados referentes a anúncios Airbnb em diversas metrópoles do mundo. Atualmente, a emergência de dados do Geoweb e Open Data permite obter informações de maneira simples, abundante e praticamente instantânea. Além disso, esses dados têm a vantagem de serem altamente atualizados, permitindo a observação de fenômenos recentes e suas evoluções. Na presente pesquisa, usaram-se dados de 2015 a 2019, para traçar um panorama evolutivo da disseminação de Airbnb na capital francesa. Desconsideraram-se os dados de 2020 devido à pandemia de Sars Covid-19, que impactou brutalmente a atividade turística na maioria das grandes cidades do mundo.

Verifica-se, a partir dos dados coletados, que os bairros apresentando uma maior proporção de apartamentos Airbnb em relação ao total de habitações disponíveis situam-se na região central de Paris, principalmente na chamada Rive Droite ${ }^{3}$ (Quadro 1). Os bairros abarcando a maior oferta proporcional de unidades, Gaillon e Bonne-Nouvelle, ficam em áreas pericentrais, caracterizadas por uma densa estrutura de transporte e fácil acesso às principais atrações turísticas da cidade. Em seguida, destacam-se igualmente bairros predominantemente turísticos como o Palais-Royal, Champs-Elysées e Marais, ${ }^{4}$ onde estão algumas das principais atrações turísticas da cidade.

\section{Quadro 1 - Bairros com o maior percentual de unidades Airbnb em Paris (extrato)}

\begin{tabular}{|l|l|}
\hline & percentual de Airbnb 2019 \\
\hline Gaillon & $18,91 \%$ \\
\hline Bonne-Nouvelle & $14,50 \%$ \\
\hline Arts-et-Métiers & $13,50 \%$ \\
\hline Archives (Marais) & $11,11 \%$ \\
\hline Enfants-Rouges (Marais) & $10,73 \%$ \\
\hline Palais-Royal (Louvre) & $10,24 \%$ \\
\hline Champs-Elysées & $8,81 \%$ \\
\hline Madeleine & $8,67 \%$ \\
\hline
\end{tabular}

fonte: Inside Airbnb ([s.d.]).

3 A expressão Rive Droite designa a porção de Paris situada ao norte do Sena, e Rive Gauche, a porção ao sul.

4 A região tradicionalmente conhecida como Marais abarca, administrativamente, os bairros Archives, Enfants-Rouges. 
Sob essa ótica, a distribuição das unidades de locação a curto prazo acompanha áreas tradicionalmente turísticas como Louvre, Champs-Elysées, Opéra, mas também bairros tradicionais, situados no coração da cidade (Figura 1). Segundo um estudo realizado por Freytag e Bauder (2018), além das áreas adjacentes aos pontos turísticos parisienses mais visitados (como a Torre Eiffel, o Arco do Triunfo, Notre-Dame), os bairros apresentando maiores evidências de turistificação seriam o Quartier Latin, o Marais e Montmartre. Tais resultados corroboram a cartografia de distribuição dos Airbnb, que se inscrevem num cenário de gentrificação e turistificação previamente consolidado nas últimas duas décadas (Gravari-Barbas; Guinand, 2017). Já os bairros periféricos, menos disputados em termos de atrações turísticas, concentram uma oferta proporcionalmente menor de unidades Airbnb.

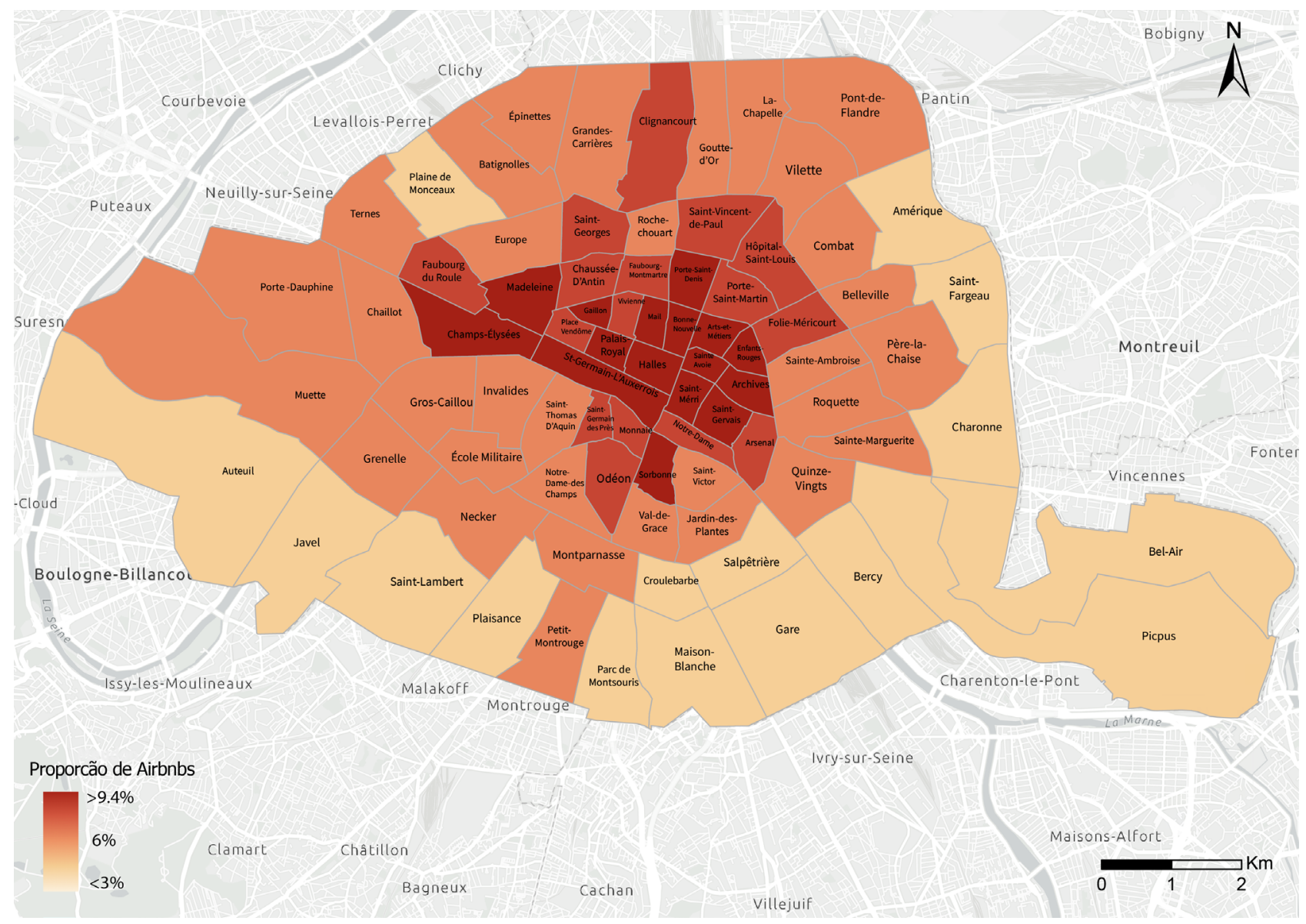

Figura 1 - Percentual de unidades Airbnb por bairro em relação ao total de habitações fonte: Elaboração própria, com dados de Inside Airbnb ([s.d.]).

Num segundo momento, observa-se a evolução da proporção de unidades Airbnb disponíveis na capital francesa de 2015 a 2019 (Quadro 2). Demonstra-se que as maiores taxas de crescimento de unidades ocorreram não só em bairros com uma oferta consolidada de locação a curto prazo, como Gaillon e Bonne-Nouvelle, ${ }^{5}$ mas também em bairros tradicionalmente populares, como Belleville e Père-Lachaise. A literatura urbana indica que estes últimos já

5 Bairros do $2^{\circ}$ arrondissement parisiense, situados na área central. 
vêm sofrendo um processo inicial de gentrificação desde a virada do século XXI, catalisado pela ascensão do Airbnb nos últimos anos. Os bairros em questão, em áreas mais periféricas da cidade, indicam uma expansão geográfica da oferta de locações Airbnb, que, saturada nos bairros turísticos centrais, traça um movimento centrífugo em direção aos bairros limítrofes de Paris, notadamente no vetor nordeste da cidade (Figura 2).

\section{Quadro 2 - Aumento do percentual de Airbnb de 2015 a 2019 (extrato)}

\begin{tabular}{|l|l|l|}
\hline & percentual de Airbnb 2019 & aumento 2015-2019 \\
\hline Quinze-Vingts & $5,06 \%$ & $173,20 \%$ \\
\hline Halles & $9,67 \%$ & $149,32 \%$ \\
\hline Belleville & $5,16 \%$ & $118,97 \%$ \\
\hline Père-Lachaise & $4,49 \%$ & $118,95 \%$ \\
\hline Enfants-Rouges (Marais) & $10,02 \%$ & $109 \%$ \\
\hline Gaillon & $18,91 \%$ & $97,44 \%$ \\
\hline
\end{tabular}

fonte: Inside Airbnb ([s.d.]).

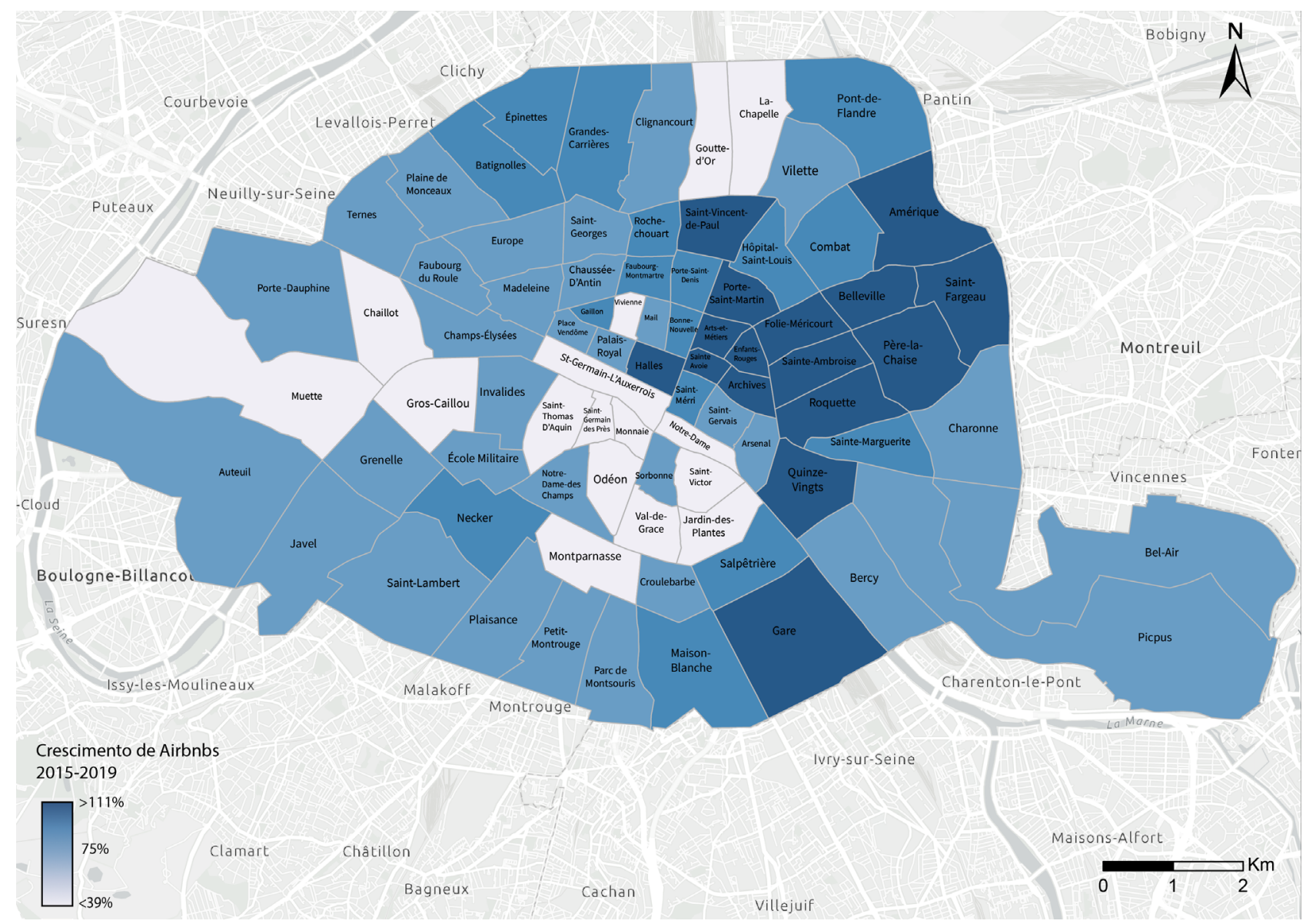

Figura 2 - Aumento de unidades Airbnb por bairro de 2015 a 2019

fonte: Elaboração própria, com dados de Inside Airbnb ([s.d.]).

Vale ressaltar que, apesar das taxas de crescimento elevadas observadas de 2015 a 2019 , a proporção de unidades Airbnb é sensivelmente menor nos bairros mais periféricos, indicando tratar-se de uma dinâmica ainda embrionária. São, porém, segundo a literatura urbana, bairros 
inscritos num etapa parcial de gentrificação, como é o caso de Belleville (Stott, 2021). Embora se verifique ali uma presença importante de trabalhadores pouco qualificados e imigrantes em relação ao restante da capital francesa, traços de gentrificação foram encontrados no bairro nas últimas duas décadas. Nesse sentido, é premente analisar a correlação entre a expansão da oferta de locação de curto prazo e os vetores de gentrificação previamente identificados na cidade-luz.

\section{Panorama da expansão do Airbnb e da gentrificação em Paris}

Num segundo momento, esta pesquisa propõe identificar possíveis tendências e correlação entre a expansão das unidades Airbnb o processo de gentrificação na capital francesa. Para tanto, procede-se a uma análise de cluster hierárquica $(\mathrm{ACH})$ para identificar os principais padrões de dispersão espacial da oferta de Airbnb, assim como a articulação dessa oferta com elementos indicativos do processo de gentrificação. A análise de clusters permite agrupar as unidades espaciais com características mais similares e distinguir as mais divergentes entre si.

Embora não exista na literatura acadêmica um consenso prévio sobre os indicadores estatísticos capazes de identificar o processo de gentrificação, uma série de variáveis sociais (renda média, categorias socioprofissionais, proporção de imigrantes, população desempregada etc.), espaciais (infraestrutura, densidade, tipos de comércio) e econômicas (valor médio dos imóveis) têm sido frequentemente utilizadas em investigações, no intuito de estimar o processo de gentrificação, em diversas partes do mundo (Galster; Peacock, 1986; Colburn; Jepson, 2012). Sob essa ótica, o presente estudo seleciona seis variáveis representativas das dinâmicas socioeconômicas e espaciais de interesse. Primeiramente, observa-se a proporção de unidades Airbnb presentes em cada bairro em 2019, assim como o crescimento dessa oferta de 2015 a 2019. Além disso, o valor médio do metro quadrado dos imóveis é analisado, assim como a evolução dos valores em questão, no período de referência. Por fim, conjuga-se os dados descritos a variáveis representativas das características socioeconômicas, como a proporção de imigrantes, renda média e a evolução da renda média por bairro de 2015 a $2018 .{ }^{6}$

\section{Quadro 3 - Variáveis utilizadas na análise de clusters}

\begin{tabular}{|l|l|l|}
\hline tema & tipo de dado & fonte \\
\hline Airbnb & $\begin{array}{l}\text { - percentual de unidades Airbnb em 2019 } \\
\text { - aumento da oferta de Airbnb de 2015 a 2019 }\end{array}$ & Inside Airbnb \\
\hline imobiliário & $\begin{array}{l}\text { - valor médio do metro quadrado por bairro } \\
\text { - evolução dos preços imobiliários de 2015 a 2019 }\end{array}$ & $\begin{array}{l}\text { Base des valeurs } \\
\text { foncières }\end{array}$ \\
\hline $\begin{array}{l}\text { características } \\
\text { socioeconômicas }\end{array}$ & $\begin{array}{l}\text { - renda média } \\
\text { - evolução da renda média de 2015 a 20187 } \\
\text { - percentual de imigrantes } \\
\text { evolução do percentual de imigrantes de 2015 a 2018 }\end{array}$ & $\begin{array}{l}\text { INSEE (Censo } \\
\text { demográfico) }\end{array}$ \\
\hline
\end{tabular}

$6 \mathrm{Na}$ escala de análise escolhida, só havia dados sobre renda média até o ano de 2018.

7 Também no Censo demográfico francês em escalas espaciais detalhadas, só havia dados até o ano de 2018. 
O primeiro grupo identificado na análise de clusters agrupa bairros centrais, tradicionalmente turísticos e de alto valor imobiliário médio por metro quadrado, como Champs-Elysées, SaintGermain des Près, Montmartre, Notre-Dame e o Marais (Figura 3). Geograficamente, os bairros apontados pertencem ao circuito turístico tradicional parisiense, concentrando-se predominantemente em áreas centrais e próximas a atrações turísticas populares. Na referida categoria, observa-se uma oferta proporcional já consolidada de unidades Airbnb, registrando as taxas mais baixas de crescimento da oferta de aluguel a curto prazo entre 2015 a 2019. Alguns bairros, como o Palais-Royal (Louvre) e a École Militaire, são objeto de um constante incremento nos valores imobiliários, enquanto outras áreas, como Notre-Dame e ChampsElysées, registram um crescimento menor, devido aos preços já elevados dos imóveis. Trata-se, igualmente, do cluster que registra a maior diminuição na proporção de imigrantes, durante período de referência, indicando uma possível expulsão das categorias desfavorecidas.

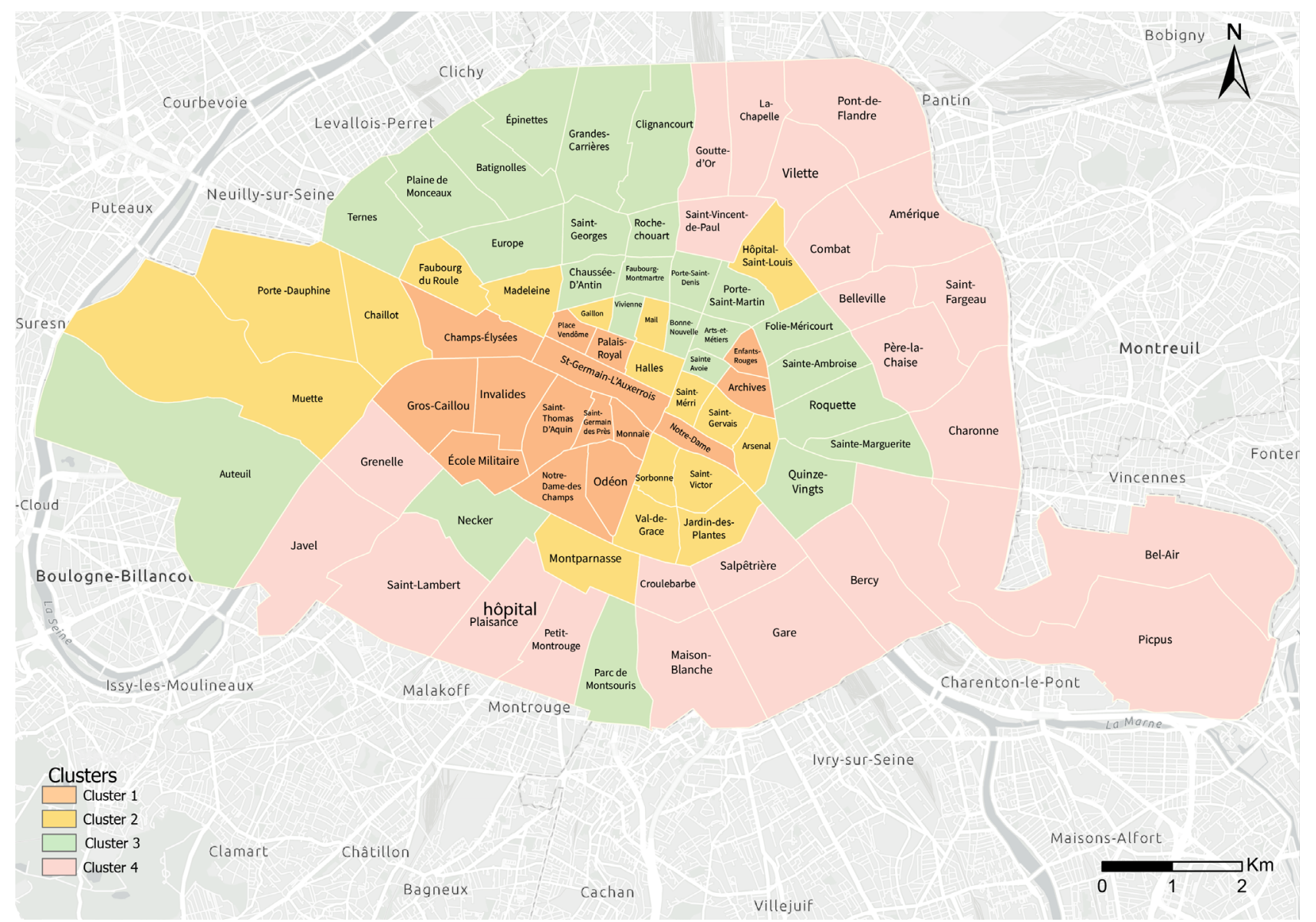

Figura 3 - Análise de cluster hierárquica

fonte: Elaboração própria, 2021.

A segunda categoria agrupa bairros centrais e pericentrais, como Halles, Montparnasse e Sorbonne, que exibiram um aumento médio de $64 \%$ de unidades Airbnb, durante período de observação. São bairros de renda média elevada, adjacentes aos pontos turísticos mais visitados e que têm sido afetados por um processo de turistificação recente (Freytag; Bauder, 2018). Assim como o cluster supracitado, verifica-se uma importante redução na proporção de imigrantes e um aumento contínuo dos preços imobiliários. 
O terceiro cluster identificado assinala bairros de renda média menos elevada, em sua maioria fora do circuito turístico do centro parisiense, que exibiram as maiores taxas de crescimento do número de unidades Airbnb, no período de análise. Assim, observa-se uma saturação da oferta de locação de curto prazo em bairros tradicionalmente turísticos e uma consequentemente expansão geográfica da oferta nos vetores leste e noroeste da cidade. Destacam-se bairros tradicionalmente populares como Montmartre e Pigalle, que têm sido objeto de processos locais de gentrificação residencial e comercial (Cerqueira, 2014). Além disso, a terceira categoria abarca bairros periféricos, de renda média menos elevada, como Épinettes e Batignolles, que sofreram grandes intervenções urbanísticas na última década (Lehman-Frisch; Authier; Dufaux, 2012).

Por fim, o quarto e último cluster engloba bairros periféricos, de ocupação tradicionalmente popular, caracterizados por uma proporção mais expressiva de imigrantes. Embora apresente uma proporção menor de unidades Airbnb em relação às unidades totais de habitação, esse grupo de bairros registrou o segundo maior crescimento proporcional da oferta de aluguéis de curto prazo nos últimos cinco anos. Ademais, inclui bairros das margens norte e sul parisienses, onde se verificaram importantes taxas de crescimento no valor médio dos imóveis de 2015 a 2019, como Belleville e Épinettes, que exibem aumentos superiores a $40 \%$ no valor médio imobiliário. Em consonância, a categoria agrupa o maior aumento de renda média dos residentes nos últimobairrs anos, evidenciando traços de gentrificação nos bairros analisados. Quanto à presença de imigrantes, há uma diminuição menos acentuada na proporção dessa categoria em comparação com os dois primeiros clusters, mostrando um processo mais lento, mas existente, de gentrificação.

\section{Articulação entre turismo e gentrificação: os casos do Marais e de Belleville}

Por fim, a seção conclusiva desta investigação introduz uma análise quantitativa da relação entre o aumento da oferta de aluguéis temporários e o processo de gentrificação, por de um breve levantamento de matérias em veículos de comunicação parisienses, complementado por uma série de entrevistas realizadas no ano de $2018^{8}$ nos bairros Marais e Belleville. Embora não seja numericamente uma extensa pesquisa qualitativa (10 entrevistas realizadas em cada bairro), as entrevistas semidiretivas procuram aferir as mudanças socioespaciais referidas por moradores e frequentadores de cada bairro e, em particular, o processo de gentrificação. Os bairros Marais e Belleville ilustram casos especialmente distintos: no primeiro, se verifica um processo de gentrificação já consolidado, contra dinâmicas embrionárias no segundo.

O Marais é um distrito caracterizado historicamente pela presença de atividades industriais e de classes operárias. Na década de 1960, o perímetro do bairro constituiu um dos primeiros setores parisienses abarcados pela política de proteção do patrimônio histórico (Gravari, 2017), criando as condições ideais para a reocupação residencial da área, que alcançou uma expressiva popularidade nos anos 1980. Dessa ótica, o processo de gentrificação do Marais implica simultaneamente a reabilitação de edifícios históricos, com a reversão da vacância comercial, e a valorização dos imóveis residenciais.

8 As entrevistas foram tomadas pelos alunos do Master Urbanisme et Aménagement, no 20 semestre de 2018. 
A Figura 4 mostra um exemplo frisante da relação entre a disseminação de aluguéis de curto prazo e o processo de gentrificação preexistente no bairro. Do lado esquerdo, observase o Marché des Enfants Rouges, mercado situado no coração do Marais, que passou por uma revitalização no final dos anos 1990. Atualmente, tornou-se um ponto de encontro dos bobos parisienses, que dividem suas mesas coletivas com turistas, em busca de experiências gastronômicas culturais. No anúncio Airbnb, observa-se que elementos como a autenticidade do mercado e a presença de novos comércios são usados como fatores de valorização turística e comercialização de unidades de aluguel temporário.

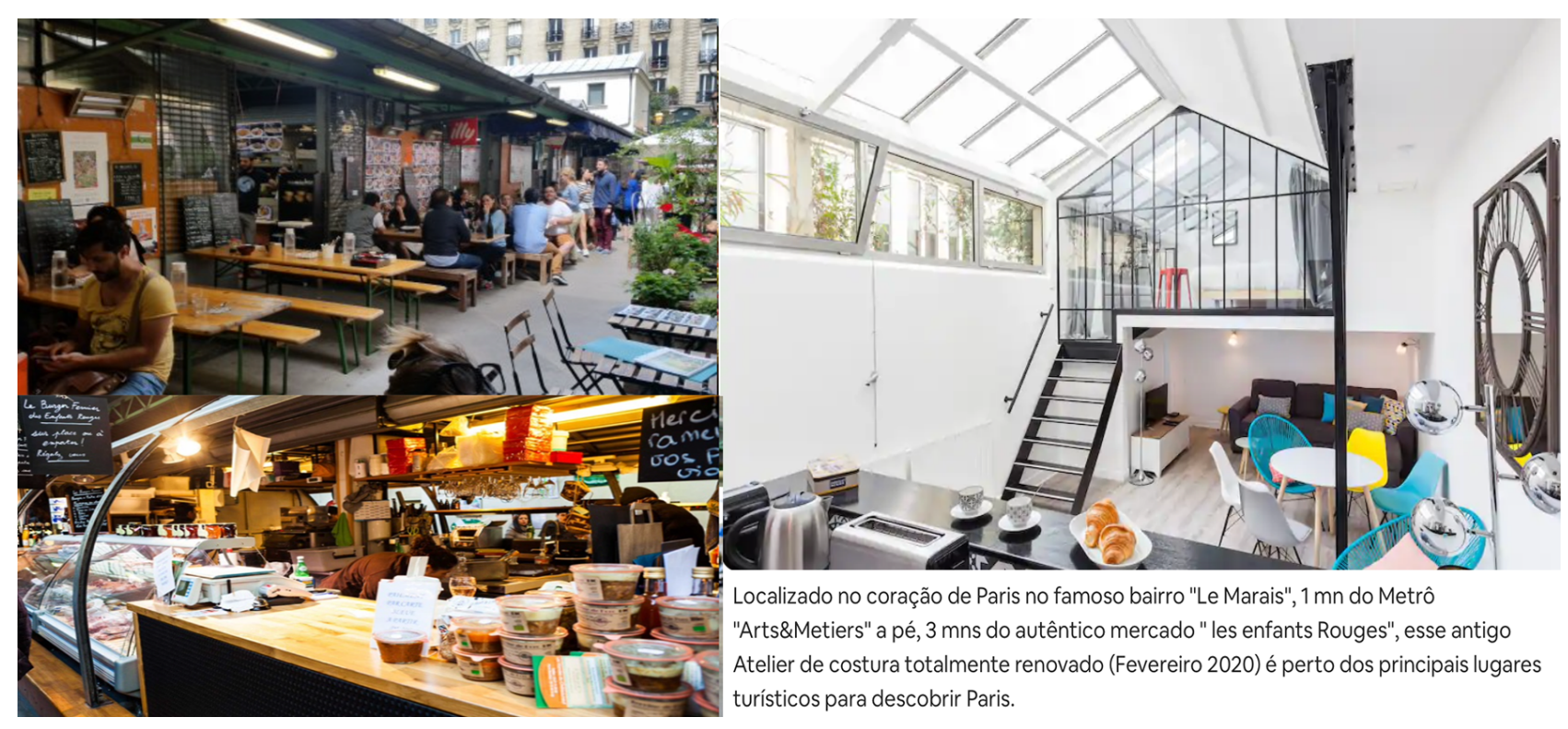

Figura 4 - Marché des Enfants Rouges e anúncio Airbnb

fonte: Fotos tiradas pela autora (à esquerda) e Airbnb (à direita).

Essa profunda relação entre a difusão de Airbnb no Marais e a gentrificação foi igualmente documentada por diversos veículos de comunicação franceses. Em 2015, o jornal Le Figaro já assinalava que, no verão de 2014, o número de locatários Airbnb hospedados no Marais teria ultrapassado seu total de habitantes. Segundo o site Univers Airbnb, o bairro figura atualmente como um dos mais afetados pela expansão das unidades de aluguel a curto prazo, ocasionando uma diminuição das unidades de locação tradicional e o consequente aumento dos preços: 0 aluguel de uma unidade de $30 \mathrm{~m} 2$ pode chegar a $€ 1500$ euros mensais. Nesses termos, o jornal ressalta que o intenso fluxo de turistas implica a perda da "alma" e da vida cotidiana do bairro.

A reconfiguração socioespacial do bairro é vista negativamente pelos moradores, que lamentam a ascensão dos preços imobiliários, a transformação do perfil de moradores e a erosão dos pequenos comércios. Uma moradora expressa esse sentimento enfatizando que, atualmente, o Marais é frequentado apenas por turistas e bobos:

Hoje em dia, morar nos Enfants Rouges é um luxo, e muitas famílias acabam tendo que ir embora, porque o metro quadrado é raro e caro. Isso condiciona cada vez mais o distrito: cada vez mais lojas de roupas, de arte, de coisas bonitas e inúteis [...] cafés e restaurantes 
medíocres e lotados para o prazer e atratividade de turistas e bobos simpáticos (moradora da rue de Turenne, 75 anos).

Sob essa ótica, os moradores do bairro procuram alimentar a vida coletiva do bairro em atividades comunitárias, resistindo às dinâmicas de gentrificação e turistificação. Segundo uma moradora da rue de Bretagne, busca-se recuperar a vida local, muito afetada pelo afluxo de turistas observado nos últimos anos:

Sempre tem um monte de atividades aqui no bairro: feira, encontros de todo tipo no Carreau du Temple. Mas o que eu prefiro é o orçamento participativo e a possibilidade que nós, habitantes do 3ème (arrondissement), temos de recuperar um pouco nosso bairro, que se tornou bastante turístico. Nós nos reapropriamos do bairro. No entanto, é uma pena, porque cada vez que um pequeno comércio fecha, sempre vai ser uma loja de roupas chiques ou uma galeria que vai abrir no lugar (moradora da rue de Bretagne, 46 anos).

Belleville, por sua vez, tem uma trajetória sensivelmente diferente dessa. É um bairro limítrofe de Paris, a que foi anexado em 1860. Historicamente, abrigou uma população majoritária de operários e trabalhadores pouco qualificados. Além disso, tornou-se uma centralidade imigrante parisiense, absorvendo populações originárias notadamente da África e da China. Nas décadas de 1960-70, as condições insalubres de habitação no bairro suscitaram a implementação de inúmeras políticas de reabilitação e a construção extensos blocos de habitação social.

Desde a virada do século XX, tem-se observado um processo inicial de gentrificação em Belleville, corolário das tendências verificadas na capital francesa. Embora a natureza da ocupação do bairro ainda seja mista (classes populares, imigrantes e classes de renda médiaalta), o afluxo de indivíduos qualificados atua como fator de atração turística da área, que, como vimos, apresentou um aumento importante das unidades Airbnb nos últimos cinco anos. No anúncio da Figura 5, a gentrificação é apontada pelo próprio site Airbnb como fator de valorização turística, em contraponto à natureza popular de Belleville. Ademais, a mistura sociocultural típica do bairro é igualmente considerada como elemento de autenticidade e, consequentemente, de atratividade.

Face ao crescente processo de gentrificação, uma matéria veiculada pelo jornal The Huffington Post usa a expressão "Belleville-Hills", aludindo ao notório bairro de alta renda em Los Angeles, Beverly Hills (Gueham, 2016). Descrevendo-o como um bairro popular que se vem transformando em "ghetto bobo", a publicação aponta tensões socioespaciais em Belleville, que se torna palco de conflito entre as classes populares, artistas, gentrifiers e turistas. $\bigcirc$ enfoque da narrativa do periódico é a implantação de uma boutique da cadeia de cosméticos Sephora na saída do metrô Belleville, como notório símbolo da gentrificação e da turistificação da área. Entretanto, os tapumes de construção que bordeiam o novo local comercial materializam os conflitos vigentes no bairro: há uma série de pichações com mensagens pouco acolhedoras aos novos empreendedores. 


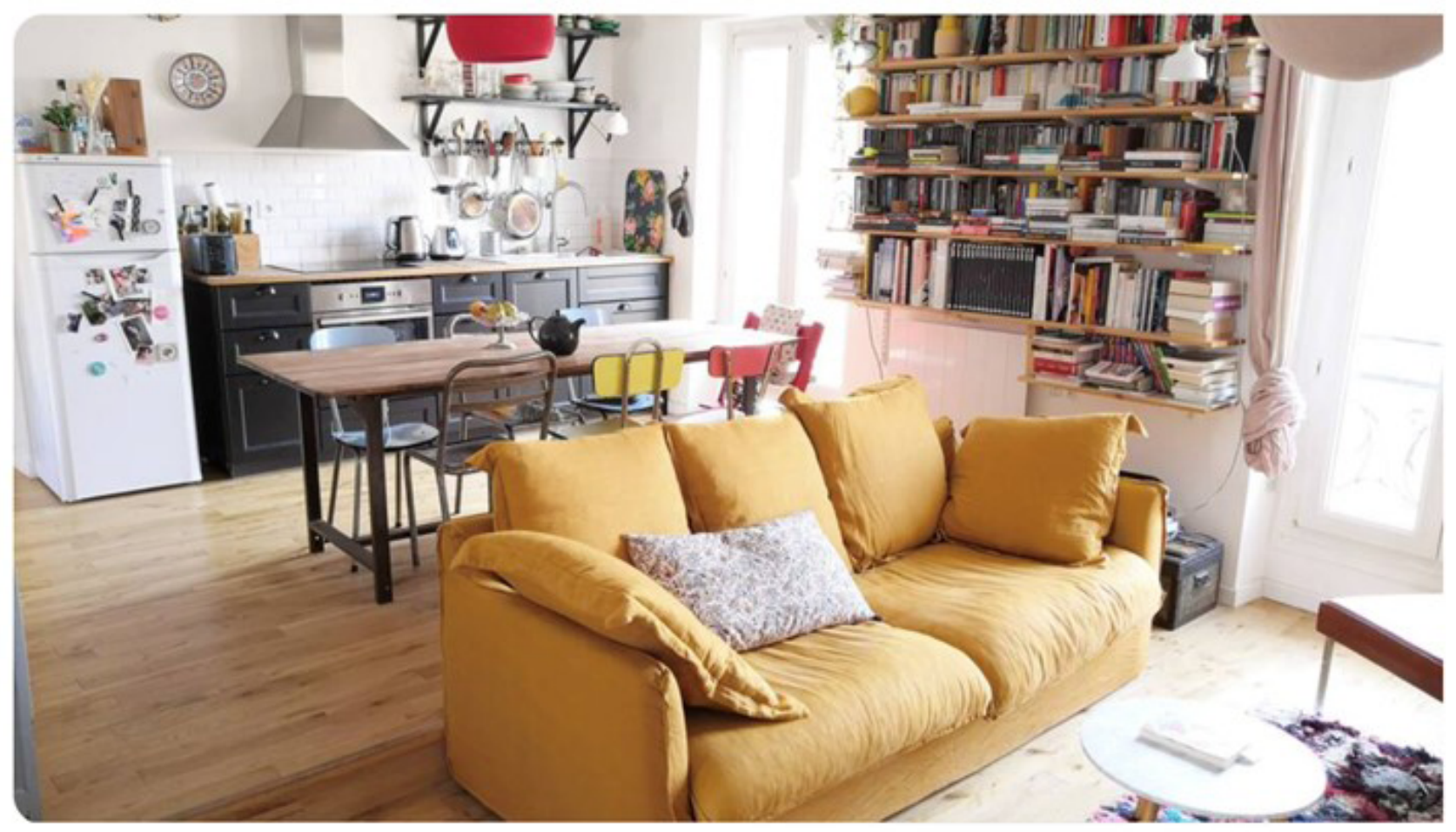

Vida noturna vibrante com muitos bares e restaurantes autênticos que oferecem culinária de todo o mundo (Belleville é um bairro historicamente diversificado, com comunidades italianas, judaicas, árabes e asiáticas, para que você possa comer uma ótima pizza, bem como almofada divina thais), e como Belleville está passando por uma rápida gentrificação, você poderá comer brunch em cafés modernos ou ter refeições finas estritamente vegana...

\section{Figura 5 - Anúncio Airbnb - Belleville}

fonte: Airbnb.

Esse cenário é ladeado pelo aumento expressivo dos preços imobiliários que, embora ainda abaixo da média parisiense, podem ultrapassar $€ 10.000$ por metro quadrado, segundo o site Meilleurs Agents. Assim, a evolução socioespacial do bairro é motivo de inquietação dos habitantes. Na pesquisa de campo realizada em 2018, eles denunciam os efeitos da gentrificação, como o desaparecimento de comércios de natureza étnica:

Eu moro em Belleville há 25 anos e te digo que os tempos mudaram. Tem várias lojinhas que desapareceram. Tinha um mercadinho turco onde eu sempre fazia compras, fechou ano passado. Os vizinhos também não são mais a mesma coisa. Hoje em dia, tem um monte de jovens, de artistas, não tem mais aquela noção de comunidade (moradora da rue Ramponeau, 56 anos).

Conforme se observa em outras cidades europeias, como Barcelona, as autoridades municipais parisienses têm tomado uma série de medidas por maior poder de intervenção no mercado privado, no intuito de mitigar o impacto da gentrificação articulada ao turismo. Em Paris, atualmente, os proprietários Airbnb podem alugar seus apartamentos por no máximo 120 dias ao ano, e a administração municipal almeja reduzir esse período para apenas 30 a 60 . No início de 2021, a prefeitura de Paris instaurou mais três importantes medidas para regulamentar o uso de unidades Airbnb. Primeiramente, os imóveis alugados que não constituem a residência primária do locador devem ser declarados como atividade comercial. Além disso, para obter a 
autorização da prefeitura, os proprietários que visam alugar seus imóveis Airbnb por um período superior a 120 dias por ano devem oferecer no mesmo bairro o correspondente em metros quadrados de habitação, de modo a preservar as unidades locativas não sazonais e mitigar a especulação imobiliária.

\section{Conclusão}

Esta pesquisa visa aferir o processo de disseminação de unidades Airbnb em Paris nos últimos anos e sua correlação com o processo de gentrificação previamente identificado na capital francesa. A dinâmica observada recentemente se inscreve num processo de turistificação no qual turismo é usado como catalisador das dinâmicas de renovação urbana, engendrando um aumento exponencial da renda e multiplicando expulsões de moradores vulneráveis e fechamento de locais comerciais tradicionais. É importante sublinhar que o surgimento do Airbnb não é a origem da gentrificação em Paris, mas catalisa o processo.

Os resultados mostram uma articulação entre o aumento expressivo da proporção de unidades Airbnb e o processo de gentrificação previamente identificado em algumas áreas da cidade. E os resultados da pesquisa quantitativa revelam que as áreas turísticas centrais têm uma oferta já consolidada de unidades de locação a curto prazo e, portanto, um aumento menor na proporção de apartamentos Airbnb de 2015 a 2019. Os bairros pericentrais, previamente atingidos por um processo expressivo de gentrificação, assistem a um intenso aumento de unidades Airbnb no período de referência. $\bigcirc$ estudo de caso do Marais ilustra a articulação entre o aumento da oferta turística, a evolução dos preços imobiliários e a expulsão de antigos residentes. Por fim, nos últimos cinco anos, verifica-se um movimento centrífugo de expansão da oferta de Airbnb em bairros tradicionalmente populares, situados em áreas periféricas de Paris. Em bairros de ocupação popular como Belleville, há uma série de tensões decorrentes do processo atual de gentrificação e turistificação. Embora o bairro ainda exiba uma expressiva mistura social (usada como fator de atratividade para turistas em unidades de aluguel temporário), identifica-se o impacto das dinâmicas descritas, como o aumento dos preços imobiliários. Nesse sentido, embora o município de Paris tenham adotado medidas atenuantes, a dinâmica de gentrificação pelo turismo continua em plena expansão na capital francesa.

Vale apontar que esses resultados têm limitações relativas aos dados censitários disponíveis do curto período analisado. Nesse sentido, sugerem-se uma continuação e um questionamento da análise nos próximos anos, a fim de estender o período de observação e dissecar mais precisamente essas dinâmicas. Por fim, podem-se questionar também as implicações da pandemia de Sars Covid-19 nas dinâmicas de turismo e no mercado de aluguel de curto prazo.

\section{Referências}

AIRBNB COMEMORA o marco de 500 milhões de chegadas de hóspedes. 27 mar. 2019. Disponível em: https://news.airbnb.com/br/airbnb-comemora-o-marco-de-500milhoes-de-chegadas-de-hospedes/. Acesso em: 12 jun. 2021. 
BLANCO-ROMERO, A.; BLÁZQUEZ-SALOM, M.; CÀNOVES, G. Barcelona, housing rent bubble in a tourist city. social responses and local policies. Sustainability, Basel, v. 10, n. 6, p. 2043-2061, 2018, doi: https://doi.org/10.3390/su10062043.

CERQUEIRA, E. D. V. A evolução das formas de gentrificação: estratégias comerciais locais e o contexto parisiense. Cadernos Metrópole, São Paulo, v. 16, n. 32, p. 417-436, 2014. doi: https://doi.org/10.1590/2236-9996.2014-3206.

CLERVAL, A. Paris sans le peuple: la gentrification de la capitale. Paris: La Découverte, 2013.

COCOLA-GANT, A.; GAGO, A. Airbnb, buy-to-let investment and tourism-driven displacement: a case study in Lisbon. Environment and Planning A: Economy and Space, v. 53, n. 7, p. 1671-1688, 2019. doi: https://doi.org/10.1177/0308518X19869012.

COLBURN, L. L.; JEPSON, M. Social indicators of gentrification pressure in fishing communities: a context for social impact assessment. Coastal Management, v. 40, n. 3, p. 289-300, 2012. doi: https://doi.org/10.1080/08920753.2012.677635.

DELGADO-MEDRANO, H.; LYON, K. Short changing New York city: the impact of Airbnb on New York City's housing market. New York: BJH Advisors LLC, 2016. Disponível em: www.mfy.org/wp-content/uploads/Shortchanging-NYC. pdf. Acesso em: 12 jun. 2021.

FOLGUEIRA, R. S.; SILVA, A. L. P.; CARVALHO, C. E. Economia do compartilhamento e custos de transação: os casos Uber e Airbnb. Pesquisa e Debate, v. 31, n. 1, p. 87-135, 2019. Disponível em: https://revistas.pucsp.br/index.php/rpe/article/ view/40293. Acesso em: 12 jun. 2021.

FREYTAG, T.; BAUDER, M. Bottom-up touristification and urban transformations in Paris. Tourism Geographies, v. 20, n. 3, p. 443-460, 2018. doi: https://doi.org/1 0.1080/14616688.2018.1454504.

GALSTER, G.; PEACOCK, S. Urban gentrification: evaluating alternative indicators. Social Indicators Research, v. 18, n. 3, p. 321-337, 1986. Disponível em: https:// www.jstor.org/stable/27520676. Acesso em: 12 jun. 2021.

GLASS, R. London: aspects of change. London: MacGibbon \& Kee, 1964.

GOTHAM, K. F. Tourism gentrification: the case of New Orleans' vieux carre (French Quarter). Urban Studies, v. 42, n. 7, p. 1099-1121, 2005. doi: https://doi. org/10.1080\%2F00420980500120881.

GRAVARI-BARBAS, M.; GUINAND, S. Tourism and gentrification in contemporary metropolises: international perspectives. [S.1.]: Taylor \& Francis, 2017.

GUEHAM, F. No-go zones: bienvenue à Belleville Hills, The Huffington Post, 5 out. 2016. Disponível em: https://www.huffingtonpost.fr/farid-gueham/no-go-zonesbelleville-hills-societe-gentrification_b_6750838.html. Acesso em: 8 out. 2021. 
GUTTENTAG, D. Airbnb: disruptive innovation and the rise of an informal tourism accommodation sector. Current Issues in Tourism, v. 18, n. 12, p. 1192-1217, 2013. doi: http://dx.doi.org/10.1080/13683500.2013.827159.

HAMARI, J.; SJÖKLINT, M.; UKKONEN, A. The sharing economy: Why people participate in collaborative consumption. Journal of the Association for Information Science and Technology, v. 67, n. 9, p. 2047-2059, 2015. doi: https://doi.org/10.1002/asi.23552.

INSIDE AIRBNB. Disponível em: www.insideairbnb.com. Acesso em: 29 jun. 2021.

LEHMAN-FRISCH, S.; AUTHIER, J.-Y.; DUFAUX, F. "Draw me your neighbourhood": a gentrified Paris neighbourhood through its children's eyes. Children's Geographies, v. 10, n. 1, p. 17-34, 2012. doi: https://doi.org/10.1080/14733285.2011.638175.

MARTINS, S. F. Turismo, gentrificação urbana e (des) alojamento local na cidade de Lisboa - Portugal. Geografia Ensino \& Pesquisa, v. 23, 2019. doi: http://dx.doi. org/10.5902/2236499437424.

MELEO, L.; ROMOLINI, A.; DE MARCO, M. The sharing economy revolution and peer-to-peer online platforms: the case of Airbnb. In: INTERNATIONAL CONFERENCE ON EXPLORING SERVICES SCIENCE, 2016. Anais... Cham, $\mathrm{CH}$ : Springer International Publishing, 2016. doi: http://dx.doi.org/10.1007/9783-319-32689-4_43.

MENDES, L. Gentrificação turística em Lisboa: neoliberalismo, financeirização e urbanismo austeritário em tempos de pós-crise capitalista 2008-2009. Cadernos Metrópole, v. 19, n. 39, p. 479-512, 2017. doi: https://doi.org/10.1590/2236-9996.2017-3906.

OSKAM, J.; BOSWIJK, A. Airbnb: the future of networked hospitality businesses. Journal of Tourism Futures, v. 2, n. 1, p. 22-42, 2016. doi: https://doi.org/10.1108/ JTF-11-2015-0048.

PERINEL, Q. Dans le Marais, plus de locataires Airbnb que d'habitants. Le Figaro, 30 maio 2016. Disponível em: https://immobilier.lefigaro.fr/article/dans-le-marais-plusde-locataires-airbnb-que-d-habitants_14dbb99c-le37-1le5-8b97-71909772d58d/. Acesso em: 7 out. 2021.

RANJBARI, M.; MORALES-ALONSO, G.; CARRASCO-GALLEGO, R. Conceptualizing the sharing economy through presenting a comprehensive framework. Sustainability, v. 10, n. 7, 2018. doi: https://doi.org/10.3390/sul0072336.

SMITH, N. The new urban frontier: gentrification and the revanchist city. Londres: Routledge, 1996.

SMITH, N. Gentrification and the Rent Gap. Annals of the Association of American Geographers, v. 77, n. 3, p. 462-465, 1987. Disponível em: https://www.jstor. org/stable/2563279. Acesso em: 12 jun. 2021. 
STOTT, C. Migration, public policy and gentrification in Belleville, Paris. Australian and New Zealand Journal of European Studies, v. 7, n. 1, p. 36-50, 2021. doi: https://doi.org/10.30722/anzjes.vol7.iss1.15152.

WACHSMUTH, D.; WEISLER, A. Airbnb and the rent gap: Gentrification through the sharing economy. Environment and Planning A: Economy and Space, v. 50, n. 6, p. 1147-1170, 2018. doi: https://doi.org/10.1177\%2F0308518X18778038.

YRIGOY, I. The impact of Airbnb in the urban arena: towards a tourism-led gentrification? The case-study of Palma old quarter (Mallorca, Spain). In: COLOQUIO DE GEOGRAFÍA DEL TURISMO: Turismo y crisis, turismo colaborativo y ecoturismo, 15., 2016. Anais... Disponível em: http://contested-cities.net/working-papers/wp-content/ uploads/sites/8/2016/07/WPCC-164010-Yrigoylsmael-ImpactAirbnbGentrification. pdf. Acesso em: 12 jun. 2021.

Recebido em: 14 jun. 2021

Aprovado em: 11 out. 2021 